\title{
Magnetic Resonance Elastography - A Novel Technique for Detection of Hepatic Fibrosis and Hepatocellular Carcinoma After the Fontan Operation
}

\author{
Joseph T. Poterucha, DO ${ }^{1}$, Jonathan N. Johnson, MD¹, Muhammad Y. Qureshi, MBBS ${ }^{1}$, \\ Patrick W. O'Leary, MD'1, Patrick S. Kamath, MD², Ryan J. Lennon, PhD ${ }^{3}$, Crystal R. \\ Bonnichsen, MD $^{4}$, Phillip M. Young, MD ${ }^{5}$, Sudhakar K. Venkatesh, MD ${ }^{5}$, Richard L. Ehman, \\ MD ${ }^{5}$, Sounak Gupta, MBBS, PhD $^{6}$, Thomas C. Smyrk, MD ${ }^{6}$, Joseph A. Dearani, MD ${ }^{7}$, Carole \\ A. Warnes, $\mathbf{M D}^{4}$, and Frank Cetta, MD ${ }^{1,4}$ \\ ${ }^{1}$ Division of Pediatric Cardiology, Department of Pediatric and Adolescent Medicine, Mayo Clinic, \\ Rochester, Minnesota, USA \\ 2Division of Gastroenterology and Hepatology, Department of Medicine, Mayo Clinic, Rochester, \\ Minnesota, USA \\ ${ }^{3}$ Division of Biomedical Statistics and Informatics, Department of Health Sciences Research, \\ Mayo Clinic, Rochester, Minnesota, USA \\ ${ }^{4}$ Division of Cardiovascular Diseases, Department of Medicine, Mayo Clinic, Rochester, \\ Minnesota, USA \\ ${ }^{5}$ Department of Radiology, Mayo Clinic, Rochester, Minnesota, USA \\ ${ }^{6}$ Department of Pathology, Mayo Clinic, Rochester, Minnesota, USA \\ ${ }^{7}$ Division of Cardiac Surgery, Department of Surgery, Mayo Clinic, Rochester, Minnesota, USA
}

\begin{abstract}
Objective-To evaluate the utility of magnetic resonance elastography (MRE) in screening patients for hepatic fibrosis, cirrhosis, and hepatocellular carcinoma after Fontan operation.

Patients and Methods-Hepatic MRE was performed in conjunction with cardiac magnetic resonance imaging in patients with prior Fontan operation between 2010-2014. Liver stiffness was calculated using previously reported techniques. Comparisons to available clinical, laboratory, imaging, and histopathologic data were made.
\end{abstract}

\footnotetext{
${ }^{1}$ Reprints and correspondence: Joseph Poterucha, DO, Division of Pediatric Cardiology, Department of Pediatric and Adolescent Medicine, Mayo Clinic, 200 First St SW, Rochester, MN 55905, Phone: 507-266-0676, Fax: 507-284-3968, poterucha.joseph@mayo.edu.

Disclosures: Richard L. Ehman and Mayo Clinic hold patents and have a financial interest from royalties related to MRE technology. All other authors have no disclosures.

Publisher's Disclaimer: This is a PDF file of an unedited manuscript that has been accepted for publication. As a service to our customers we are providing this early version of the manuscript. The manuscript will undergo copyediting, typesetting, and review of the resulting proof before it is published in its final citable form. Please note that during the production process errors may be discovered which could affect the content, and all legal disclaimers that apply to the journal pertain.
} 
Results-Overall, 50 Fontan patients aged 25 (21-33) years were evaluated. The median interval between Fontan creation and MRE was 22 (16-26) years. Mean liver stiffness values were increased; 5.5 \pm 1.4 kilopascals relative to normal subjects. Liver stiffness directly correlated with liver biopsy total fibrosis score, time since operation; mean Fontan pressure; $\gamma$-glutamyl transferase (GGT); MELD score; creatinine; and pulmonary vascular resistance index (PVR). Liver stiffness was inversely correlated with cardiac index (CI). All 3 subjects with hepatic nodules exhibiting decreased contrast uptake on delayed post-contrast imaging and elevated nodule stiffness had biopsy-proven hepatocellular carcinoma.

Conclusion-The association between hepatic stiffness and fibrosis scores, MELD scores, and GGT, suggests that MRE may be useful to detect (and possibly quantify) hepatic cirrhosis in Fontan patients. Correlation between stiffness and post-Fontan time interval, mean Fontan pressure, PVR and reduced CI suggests a role for long term hepatic congestion in creating these hepatic abnormalities. MRE was useful in detecting abnormal nodules ultimately diagnosed as hepatocellular carcinoma. The relationship between stiffness with advanced fibrosis and hepatocellular carcinoma provides a strong argument for additional study and broader application of MRE in these patients.

\section{Keywords}

Cardiovascular disease; liver disease; malignancy; carcinoma; magnetic resonance imaging

\section{Introduction}

Functionally single ventricle anatomy represents roughly $8 \%$ of all patients with congenital heart disease with a birth incidence of 4-8 per 10,000. ${ }^{1}$ The Fontan operation was originally described in 1968 by the French cardiac surgeon Francis Fontan for repair of such patients afflicted with this lesion. ${ }^{1}$ Nearly all patients with functionally single ventricles are expected to undergo the Fontan operation. ${ }^{2}$ This operation represents $4.2 \%$ of all congenital heart surgeries performed in the United States. ${ }^{2}$ This palliative operation consists of various surgeries to entirely reroute systemic bi-caval venous return directly into the pulmonary arterial confluence -effectively bypassing the sub-pulmonary ventricle (Figure 1). ${ }^{3,4}$ The resultant non-pulsatile passive venous filling of the pulmonary arterial bed results in markedly elevated central venous pressure. This elevated central venous pressure can increase the afterload experienced by the liver and in combination with the inherent low cardiac output state of patients after Fontan operation, lead to congestive hepatopathy (Figure 2) 3 ,4

Hepatic dysfunction after the Fontan operation frequently has an indolent subclinical course. Liver fibrosis often precedes laboratory or ultrasonographic imaging abnormalities and many patients may remain free of clinical signs of cirrhosis until late stages of hepatic dysfunction. Most concerning is the report that some patients have developed hepatocellular carcinoma. ${ }^{3,4}$ There is no gold standard assessment for cirrhosis after the Fontan. Liver biopsy is the gold standard for diagnosis of hepatic fibrosis and cirrhosis in routine adult hepatology practices. ${ }^{5,6}$ However, liver biopsy is limited by intra- and inter-observational variability in interpretation, sampling error due to the non-homogenous pattern of hepatic fibrosis, high cost and need for anesthesia or sedation. ${ }^{7-10}$ Consequently, clinicians have 
sought other noninvasive ways of assessing degree of fibrosis after the Fontan operation, including techniques utilizing elastography.

Magnetic resonance elastography (MRE) has emerged as a cost-effective advanced screening tool for pre-clinical detection of hepatic fibrosis and cirrhosis in patients with noncardiac liver disease. ${ }^{10}$ It has also shown promise as a tool for screening suspicious liver nodules. ${ }^{9}$ However, data examining the role of MRE in patients with congestive hepatopathy are limited. The aim of this investigation was to determine the spectrum of MRE derived liver stiffness in patients after the Fontan operation and identify stiffness correlates with hemodynamic, pathologic, clinical and laboratory data.

\section{Methods}

\section{Study Design and Patient Population}

Patients after Fontan operation, who were referred for liver evaluation at Mayo Clinic between January 1, 2010 and January 31, 2014, were retrospectively evaluated. Patients were identified by searching the radiology and Fontan databases at our institution. The study protocol was approved by Mayo Clinic Institutional Review Board. Written research consent was obtained from patients and guardians of pediatric aged patients at the time of clinic evaluation. Assent was obtained from subjects under 18 years of age. Some patient data $(\mathrm{n}=10)$ was previously described. ${ }^{9}$ Clinical, imaging, hemodynamic, and liver biopsy data were collected at the time of hepatology evaluation. Heterotaxy was defined as bilateral right or left sidedness of the abdominal viscera (asplenia or polysplenia). Fontan fenestration was defined as a surgically created hole between the Fontan conduit and pulmonary venous atrium.

\section{MRI Technique}

Cardiac magnetic resonance imaging (MRI) was obtained using a 1.5 T MRI unit (HDx Twin Speed or 450w, General Electric Healthcare, Waukesha, WI, USA). Patients fasted for six hours before MRI. Cardiac MRI was performed with additional liver sequences for MRE, including an axial T2-weighted fast spin echo sequence, respiratory triggered multishot multi-b-value diffusion-weighted sequence (b100 and b600), a dual echo in an opposed phase T1-weighted gradient recalled echo (GRE) sequence, and post-contrast dynamic T1weighted sequences. Liver sequences were assessed for features suggestive of nodular liver, caudate lobe hypertrophy, and volumetric changes consistent with fibrosis and cirrhosis. ${ }^{9-11}$

\section{MRE}

MRE of the liver was performed at the conclusion of the Cardiac MRI study as an additional sequence according to methods previously described. ${ }^{10}$ MRE was performed with the patient in the supine position, placing a $19 \mathrm{~cm}$ disc pneumatic passive driver on the right lower chest and anterior abdomen, and connecting it to an active driver with plastic tubing. ${ }^{10}$ Acoustic vibrations were generated at a frequency of $60 \mathrm{~Hz}$ by the active driver using an audio subwoofer and transmitted to the pneumatic passive driver (Figure 3). The transmitted acoustic waves produce propagating shear waves in the upper abdomen and the liver. These propagating shear waves were imaged using two-dimensional GRE MRE sequence with the 
following scan parameters TR/TE $=50 / 24 \mathrm{~ms}$; flip angle $30^{\circ}$, matrix $256 \times 128$, and an asymme tric $75 \%$ field of view adjusted to fit each patient, variable field of view $=30$ to 48 $\mathrm{cm}$. Stiffness maps were automatically generated on the scanner using the raw magnitude and phase images by an inversion algorithm. Four $10 \mathrm{~mm}$ thick slices in the axial plane were prescribed at the largest cross-sectional area of the liver and acquired with 12-16 second breath hold at end expiration in an effort to ensure reproducibility (Figure 4). ${ }^{10}$ Image quality was immediately verified by observing propagating shear waves in the phase images after acquisition on the MRI console. ${ }^{9-11}$ The MRE, including interpretation, added less than two minutes to the cardiac MRI (four 10-15 second breath holds).

\section{MRE Image Analysis and Stiffness Measurement}

Measurements were performed on standalone workstations by an independent reader unaware of the liver histology results and other clinical details. The liver stiffness was measured by placing automated regions of interest (ROI) of at least $100 \mathrm{~mm}^{2}$ on the elastogram with care to avoid the liver edge, artifacts and large vessels greater than $3 \mathrm{~mm}$ in size. ROIs were performed on all four slices obtained and a mean stiffness value was obtained. Multiple regions of interest were performed to ensure large volume of liver being assessed. Mean liver stiffness was expressed in kilopascals $(\mathrm{kPa}){ }^{9-11}$

\section{Hemodynamic Catheterization Evaluation}

Thirty patients with severe systemic desaturation or suspected obstruction in the Fontan conduit or pulmonary arteries had cardiac catheterization. Hemodynamic measurements collected included hepatic vein pressure, hepatic venous wedge pressure, hepatic venous pressure gradient, Fontan pressure, pulmonary artery pressure, ventricular end diastolic pressure, pulmonary capillary wedge pressure, cardiac index, and pulmonary vascular resistance index. Portal venous pressure was estimated by calculating the hepatic venous pressure gradient using the following calculation: hepatic venous pressure gradient $=$ hepatic venous wedge pressure - hepatic vein pressure. Conventional angiography was obtained to identify evidence of veno-venous collaterals, residual shunts, and Fontan pathway stenoses (defined as a gradient above $2 \mathrm{mmHg}$ within the circuit).

\section{Echocardiographic Data}

Two-dimensional spectral and color Doppler techniques were used to identify evidence of obstruction or residual shunt in the Fontan conduit and assess ventricular function. Valvular regurgitation or stenosis was graded as mild, moderate, and severe based on qualitative assessment.

\section{Laboratory studies and Cirrhosis Prognostic Indices}

All patients had laboratory studies for hepatology evaluation. These tests included: aspartate aminotransferase (AST); alanine aminotransferase (ALT); alkaline phosphatase; total protein; albumin; total and direct bilirubin; $\gamma$-glutamyl transferase (GGT); alpha-fetoprotein; international normalized ratio (INR); platelet count; hemoglobin; creatinine; and hepatitis A, $\mathrm{B}$, and $\mathrm{C}$ serologies. Blood samples were obtained after a 6 hour fasting period. AST to Platelet Ratio Index was calculated with the following formula: (AST/upper limit of normal 
$\times 100) /$ platelet count, with AST level of $43 \mathrm{IU} / \mathrm{L}$ used as the upper limit of normal. The Model for End-Stage Liver Disease (MELD) score, MELD-XI (excluding INR), ChildTurcotte-Pugh score, and Atlanta varices, ascites, splenomegaly, thrombocytopenia (VAST) score were calculated to assess chronic liver disease.

\section{Liver Biopsy}

Percutaneous or transcatheter (transjugular or transfemoral) liver biopsy was obtained in patients with nodules suspicious for malignancy or at the discretion of the hepatologist. Two pathologists specializing in hepatology (SG and TCS), who were blinded to patient data, independently reviewed liver biopsy specimens. Portal fibrosis was graded using the Ishtak (stages 0-6) and Scheuer staging (stages 0-4) systems; and sinusoidal fibrosis was determined using staging described by Schwartz et al. ${ }^{12,13}$ Total fibrosis score was calculated by combining the grades of staging of all three staging techniques.

\section{Statistical Analysis}

Data were expressed as mean \pm SD or median $\left(25^{\text {th }}-75^{\text {th }}\right.$ interquartile range $)$ according to level of skew, or total number plus percentages. One-way analysis of variance test was performed to compare differences in liver and spleen stiffness among patients according to Fontan type, as well as by those with a surgical fenestration, who underwent Fontan conversion, had esophageal varices, nodules demonstrating biopsy proven hepatocellular carcinoma, patients with veno-venous collaterals, and those patients with underlying heterotaxy syndrome. To compare matched paired differences in spleen and liver stiffness in the entire cohort, a paired t-test was utilized. Correlations between liver and spleen stiffness with continuous clinical measures were summarized with Pearson's correlation coefficient and tested by simple linear regression. For all statistical analyses a $P$ value less than .05 was deemed statistically significant. All data analysis was performed by a statistician (RJL) with JMP (SAS Institute Inc., SAS Campus Drive, Cary, North Carolina, 27513, USA.)

\section{Results}

\section{Patient Characteristics}

Baseline patient characteristics are described in table 1. A total of 50 patients with prior Fontan operation, 25/50 (50\%) female, median age 25 (21-33) years were identified. Cardiac anatomy included 30/50 (60\%) patients with left ventricular morphologic (double inlet left ventricle, $\mathrm{n}=16$; tricuspid atresia, $\mathrm{n}=12$; pulmonary atresia with intact ventricular septum, $\mathrm{n}=1$; and unbalanced atrioventricular septal defect with left ventricular dominance, $\mathrm{n}=1$ ); $20 / 50(40 \%)$ patients with right ventricular morphologic (double outlet right ventricle with mitral atresia, $\mathrm{n}=8$, hypoplastic left heart syndrome, $\mathrm{n}=6$; unbalanced atrioventricular septal defect with right dominance, $n=5$; and double inlet right ventricle, $n=1$ ). Six patients had heterotaxy syndrome (all asplenia). There were three deaths in this cohort during follow-up, all in patients with hepatocellular carcinoma (including one patient with heterotaxy). Two other patients had transplantation (one heart-liver for hepatocellular carcinoma and one heart transplantation alone for protein losing enteropathy); and five patients had been listed for transplant at the time of this review (all four listed for heart-liver due to chronic combined systolic and diastolic heart failure along with cirrhosis; one listed 
for heart for refractory atrial arrhythmias and diastolic heart failure). A total of 7/50 (14\%) patients had received potentially hepatotoxic medications: amiodarone $(\mathrm{n}=3)$, prednisone ( $\mathrm{n}$ $=2)$, and methimazole $(\mathrm{n}=2)$.

\section{Surgical History}

The types of Fontan connection included atrio-pulmonary (AP) in 20/50 (40\%) patients, lateral tunnel in 17/50 (34\%), and extracardiac conduit in 13/50 (26\%). Mean interval from Fontan to hepatology evaluation was $21 \pm 7$ years. Interval from Fontan to first hepatology evaluation was longer with AP connection ( $28 \pm 5$ years) compared to lateral tunnel (20 \pm 4 years) and extracardiac Fontan connection $(14 \pm 5$ years $)(P<.01)$ (Table 1). Seventeen patients of fifty patients (34\%) had patent Fontan fenestrations at time of hepatology evaluation.

\section{Hemodynamic Catheterization Data}

Hemodynamic data are shown in table 2 . These data were available in 30 patients. Cardiac catheterization was performed a mean of $4 \pm 3$ months before or after MRE. The mean resting cardiac index was $2.4 \mathrm{~L} / \mathrm{min} / \mathrm{m}^{2}$. Mean Fontan pressure was $16 \pm 4 \mathrm{mmHg}$; mean pulmonary capillary wedge pressure was $10 \pm 3 \mathrm{mmHg}$; and ventricular end diastolic pressure was $12 \pm 3$ $\mathrm{mmHg}$. The mean pulmonary vascular resistance index was $3 \pm 1 \mathrm{Wood}$ Units $\cdot \mathrm{m}^{2}$. Mean aortic saturations were $90 \pm 5 \%$. The hepatic vein pressure and hepatic venous wedge pressure were elevated at $17 \pm 3$ and $19 \pm 5 \mathrm{mmHg}$ respectively, while the hepatic venous pressure gradient was at $2 \pm 1 \mathrm{mmHg}$. Fontan pathway stenosis was present in $11 / 50$ (22\%) patients (covered stents were placed in 2 patients). Systemic veno-venous collaterals were present in 24/50 (48\%) patients (5 patients had prior embolization), and pulmonary arteriovenous malformations were present in 5/50 (10\%) patients. Echocardiographic data are described in table 2 .

\section{Cardiac MRI/MRE Findings}

MRI data are described in table 3. Hepatic imaging revealed nodularity in 34/50 (68\%) patients caudate lobe hypertrophy in 26/50 (52\%), lobar atrophy in 19/50 (38\%), and hepatomegaly in $30 / 50(60 \%)$. There were a total of 21 nodules identified in 13/50 (26\%) patients. Eight of 21 nodules (38\%) had decreased contrast uptake on delayed post-contrast imaging (suggestive of malignancy). Three of these 8 nodules had biopsy proven hepatocellular carcinoma (Table 3).

\section{Laboratory Results and Cirrhosis Clinical Indices}

Laboratory and liver data are described in table 3. Of note, mean GGT value was $96 \pm 54 \mathrm{U} / \mathrm{L}$ which was elevated to two times the upper limit of normal. Thirty-nine of $50(78 \%)$ patients had hepatitis A, B and C serologies available. Three patients were hepatitis $\mathrm{C}$ positive, and two had hepatocellular carcinoma. The AST to Platelet Ratio Index was elevated above normal; to levels consistent with fibrosis. The MELD, MELD-XI, Child-Turcotte-Pugh, and VAST score were elevated. 


\section{Histopathologic Findings}

Liver biopsies were available in 10/50 (20\%) patients. Eight of these were considered adequate for pathologic interpretation. Indications for liver biopsy were: suspicious nodules $(n=4)$, pre-cardiac transplant liver surveillance for cirrhosis $(n=3)$, cirrhotic configuration on MRI ( $n=2)$, hepatomegaly on ultrasound $(n=1)$. Pathologic data are shown in Table 4. MRE liver stiffness and spleen stiffness strongly correlated with histologic grade of fibrosis $(\mathrm{R}=$ $0.74, P=.02 ; \mathrm{R}=0.97, P=.002$ ) (Figure 5). Three patients had targeted biopsies of specific lesions that revealed hepatocellular carcinoma.

\section{Stiffness analysis}

MRE data are demonstrated in table 5. All 50 MREs were interpretable with $100 \%$ technical success. Mean liver and spleen stiffness were $(5.5 \pm 1.4$ and $8.2 \pm 2.8 \mathrm{kPa}$ ) respectively (Table 5). There were no significant differences in mean liver stiffness based on type of Fontan connection, ventricular morphology, or history of prior Fontan conversion. Patients with a fenestration at the time of Fontan operation had significantly decreased mean liver stiffness ( $4.8 \pm 0.3$ vs. $5.8 \pm 0.2, P=.01)$ and spleen stiffness $(6.6 \pm 0.7$ vs. $9.0 \pm 0.5, P=.001)$ relative to non-fenestrated patients (Table 5). The presence of varices were associated with increased liver stiffness (5.9 \pm 0.2 vs $4.9 \pm 0.3, P=.02)$ and spleen stiffness $(9.2 \pm 0.6$ vs. $7.0 \pm 0.6, P=.01)$ compared to those without varices (Table 5). The presence of veno-venous collaterals was associated with an increased liver stiffness compared to those without collaterals (5.9 \pm 0.3 vs. 5.1 $\pm 0.3, P=.04)$ (Table 5). Mean spleen stiffness was higher than liver stiffness among all patients in the cohort and in each type of Fontan connection (Table 5).

Three patients (ages 33, 42, and 23 years old [mean liver stiffness: $6.8 \mathrm{kPa}, 7.4 \mathrm{kPa}$, and 8.2 $\mathrm{kPa}$ respectively]) with multiple nodules exhibiting decreased contrast uptake on delayed post-contrast imaging, and were ultimately found to have hepatocellular carcinoma on biopsy. Among the patients with nodules, those with malignant nodules had increased mean liver stiffness compared to those with benign nodules $(10.8 \pm 4.7$ versus $4.0 \pm 1 \mathrm{kPa} ; P=.01)$.

Increase liver stiffness correlated with total fibrosis score, time since Fontan operation, Fontan pressure, GGT, MELD score, creatinine and pulmonary vascular resistance index and was inversely correlated with catheterization derived cardiac index (Figure 6). Spleen stiffness was directly correlated with splenic volume $(\mathrm{R}=0.34, P=.03)$. GGT correlated with Fontan pressure ( $\mathrm{R}=0.66, P=.03)$, AFP $(\mathrm{R}=0.72, P=.04)$, AST-platelet ratio ( $\mathrm{R}=$ $0.34, P=.03)$, and splenomegaly $(\mathrm{R}=0.43, P=.04)$. No other correlations were noted among all other clinical, imaging, hemodynamic, or laboratory variables.

\section{Discussion}

We report a large study of MRE in patients after Fontan operation with concomitant assessment of hemodynamic and histopathologic data. Our observations suggest that MRE may be an important early detection tool for congestive cirrhosis after Fontan. We also found that liver stiffness was associated with progressive fibrosis and this appeared to be a time dependent phenomenon. 
In contrast to previous reports of patients with non-cardiac cirrhosis, few patients in this cohort had symptomatic cirrhosis. We speculate that passive congestion from elevated central venous pressure may result in a greater degree of stiffness, as measured by MRE, in Fontan patients relative to non-cardiac cirrhotic patients. This may account for the more indolent sub-clinical progression of cirrhosis in patients after Fontan operation. The association of stiffness, fibrosis scores and suboptimal hemodynamics (lower cardiac output, higher mean Fontan pressure and pulmonary resistance) leads us to believe that chronically elevated central venous pressure, in concert with impaired hepatic perfusion is likely to be the mechanism of hepatocyte injury causing fibrosis and progression to cirrhosis. ${ }^{9,14-18}$ in these patients. This was further supported by the advanced degree of peri-sinusoidal fibrosis observed in this cohort. These hepatic cells most are the most vulnerable to ischemic injury in a low cardiac output state (Figure 7).

We demonstrated that MRE is a useful tool for prognostic assessment of hepatic fibrosis and a screening tool for hepatocellular carcinoma. At nearly 20 years after Fontan operation, excluding those with HCC, no patient was noted to have progressive end-stage cirrhosis. Other institutions have advocated routine liver biopsy 10 years after Fontan. ${ }^{19}$ While liver biopsy remains the gold standard for diagnosis of cirrhosis, it carries invasive risk of adverse events, poor patient compliance, additional cost, and problems with sampling error and variability by histologic assessment. ${ }^{7,10,11,20}$ Early invasive biopsy in children may be avoided by MRE assessment beginning at 10 years after Fontan. MRE may serve as a method to reserve invasive evaluations such as biopsy to a smaller group of pts in whom the data is most likely to impact their management. Such surveillance for detection of hepatic fibrosis may yield an opportunity to institute medical, catheterization based, or surgical therapy to decrease hepatic afterload in an effort to avoid progression to cirrhosis and eventual need for heart-liver transplantation. MRE may also direct which segment of the liver to target when biopsy is performed, as was done in all of our patients undergoing liver biopsy. Here, our institution proposes a Fontan liver diagnostic evaluation for detection and surveillance of cirrhosis utilizing MRE (Figure 8).

\section{Differentiation of Benign Versus Malignant Liver Nodules}

MRE was useful for characterization of liver nodules. A study of 44 hepatic masses in 29 patients showed that malignant tumors had elevated mean stiffness values compared to benign tumors $(10.1 \mathrm{kPa}$ versus $2.7 \mathrm{kPa}, P<.01) .{ }^{10,20}$ In the current study, 10 patients had suspicious liver nodules. Suspicious dynamic enhancement features, mild T2 hyperintensity, arterial phase hypervascularity, and washout of intravenous contrast and reduced hepatocyte contrast uptake that are findings typical for hepatocellular carcinoma, were seen in five patients (Figure 9). Patients with malignant nodules had increased mean liver stiffness compared to those with benign nodules $(P=.01)$. MRE may aid in detecting malignant nodules and also may guide targeted liver biopsy rather than random sampling.

\section{GGT - Potential Biomarker for Cirrhosis after Fontan Operation?}

GGT has not previously been demonstrated to correlate with degree of hepatic fibrosis in patients after Fontan prior to this study. Other standard laboratory indices for hepatic dysfunction are frequently normal or minimally increased in patients after Fontan operation. 
GGT directly correlated with liver stiffness, and also correlated with Fontan pressure, ASTplatelet ratio, and splenomegaly. Venous outflow impairment can result in ductal proliferation. ${ }^{21-23}$ GGT is present in bile duct endothelial cells, and is elevated in scenarios of biliary blockage and ductal proliferation. ${ }^{21-23}$ We speculate that GGT may be a novel biomarker for progression of hepatic fibrosis or simply reflective of progressive central venous (Fontan) pressure elevation. GGT may also add significantly as a screening tool in addition to MRE to aid in determining which patients require liver biopsy.

\section{Limitations}

Unfortunately only a few of the patients in the cohort had liver biopsy samples that could be correlated with the other data obtained. Despite this, we were still able to demonstrate that the degree of fibrosis increased as MRE stiffness values increased. A larger cohort is needed to define a "severity" scale for estimating fibrosis based on stiffness in Fontan patients, but our observations would suggest that this type of grading scale is not only possible, but also likely to be clinically useful. It is possible that stiffness after Fontan is likely related to both elevated central venous pressure and fibrosis. Prospective study examining stiffness in patients with similar central venous pressure at baseline shortly after Fontan and long term will need to be undertaken to determine how much stiffness is congestion versus hepatic disease.

The incidence of hepatitis C may be underestimated in this cohort, since $20 \%$ of patients were not screened for infectious hepatitis. Our patient population was older (mean age $=28$ years old) and most were older than age 4 years at the time of Fontan operation. Future study should involve evaluating the entire age spectrum of patients following the Fontan operation, instead of a predominately older cohort referred for liver evaluation, to adequately determine the effect of age on stiffness.

\section{Conclusion}

We present a large study concomitantly assessing clinical, histopathologic, and hemodynamic data after Fontan operation with MRE. The association between hepatic stiffness and fibrosis scores, MELD scores, and GGT, suggests that MRE may be useful to detect (and possibly quantify) hepatic cirrhosis in Fontan patients. Correlation between stiffness and post-Fontan time interval, mean Fontan pressure, PVR and reduced CI suggests a role for long term hepatic congestion in creating these hepatic abnormalities. The relationship between stiffness with advanced fibrosis and hepatocellular carcinoma provides a strong argument for additional study and broader application of MRE in these patients. Based on this experience, MRE deserves further study to determine appropriate "normal" MRE values for patients with high central venous pressure. MRE may provide a powerful yet non-invasive method for screening patients after Fontan operation for hepatic fibrosis without biopsy.

\section{Acknowledgments}

Todd and Karen Wanek Program for Hypoplastic Left Heart Syndrome, Mayo Clinic Foundation. 
Funding sources: Supported from NIH grant EB001981 and Todd and Karen Wanek Program for Hypoplastic Left Heart Syndrome, Mayo Clinic Foundation.

\section{References}

1. O'Leary PW. Prevalence, clinical presentation, and natural history of patients with single ventricle. Prog pediatr cardiol. 2002; 16:31-38.

2. Jacobs JP, Maruszewski B. Functionally univentricular heart and the fontan operation: lessons learned about patterns of practice and outcomes from the congenital heart surgery databases of the European association for cardiothoracic surgery and the society of thoracic surgeons. World J Pediatr Congenit Heart Surg. 2013; 4:349-55. [PubMed: 24327626]

3. Kutty SS, Peng Q, Danford DA, et al. Increased hepatic stiffness as consequence of high hepatic afterload in the Fontan circulation: a vascular Doppler and elastography study. Hepatology. 2014; 59:251-60. [PubMed: 23913702]

4. Wu FM, Ukomadu C, Odze RD, Valente AM, Mayer JE Jr, Earing MG. Liver disease in the patient with Fontan circulation. Congenital heart disease. 2011; 6:190-201. [PubMed: 21443554]

5. Ginde S, Hohenwalter MD, Foley WD, et al. Noninvasive assessment of liver fibrosis in adult patients following the Fontan procedure. Congenital heart disease. 2012; 7:235-42. [PubMed: 22360766]

6. Bulut OP, Romero R, Mahle WT, et al. Magnetic resonance imaging identifies unsuspected liver abnormalities in patients after the Fontan procedure. The Journal of pediatrics. 2013; 163:201-6. [PubMed: 23391043]

7. Bedossa P, Dargere D, Paradis V. Sampling variability of liver fibrosis in chronic hepatitis C. Hepatology. 2003; 38:1449-57. [PubMed: 14647056]

8. Friedrich-Rust M, Koch C, Rentzsch A, et al. Noninvasive assessment of liver fibrosis in patients with Fontan circulation using transient elastography and biochemical fibrosis markers. Journal of thoracic and cardiovascular surgery. 2008; 135:560-567. [PubMed: 18329470]

9. Serai SD, Wallihan DB, Venkatesh SK, et al. Magnetic resonance elastography of the liver in patients status-post fontan procedure: feasibility and preliminary results. Congenital heart disease. 2014; 9:7-14. [PubMed: 24134059]

10. Venkatesh SK, Yin M, Ehman RL. Magnetic resonance elastography of liver: technique, analysis, and clinical applications. Journal of magnetic resonance imaging. 2013; 37:544-55. [PubMed: 23423795]

11. Venkatesh SK, Wang G, Lim SG, Wee A. Magnetic resonance elastography for the detection and staging of liver fibrosis in chronic hepatitis B. European radiology. 2014; 24:70-8. [PubMed: 23928932]

12. Schwartz MC, Sullivan LM, Glatz AC, et al. Portal and sinusoidal fibrosis are common on liver biopsy after Fontan surgery. Pediatric cardiology. 2013; 34:135-42. [PubMed: 22695765]

13. Evans WN, Winn BJ, Yumiaco NS, et al. Transvenous hepatic biopsy in stable fontan patients undergoing cardiac catheterization. Pediatric cardiology. 2014; 35:1273-8. [PubMed: 24817681]

14. Johnson JA, Cetta F, Graham RP, et al. Identifying predictors of hepatic disease in patients after the Fontan operation: a postmortem analysis. The Journal of thoracic and cardiovascular surgery. 2013; 146:140-5. [PubMed: 23072704]

15. Wu FM, Opotowsky AR, Raza R, et al. Transient Elastography May Identify Fontan Patients with Unfavorable Hemodynamics and Advanced Hepatic Fibrosis. Congenital heart disease. 2014; 9(5): 438-47. [PubMed: 24418160]

16. Camposilvan S, Milanesi O, Stellin G, Pettenazzo A, Zancan L, D’Antiga L. Liver and cardiac function in the long term after Fontan operation. Annals of thoracic surgery. 2008; 86:177-182. [PubMed: 18573420]

17. Shah H, Kuehl K, Sherker AH. Liver disease after the Fontan procedure: what the hepatologist needs to know. Journal of clinical gastroenterology. 2010; 44:428-31. [PubMed: 20216078]

18. Kiesewetter $\mathrm{CH}$, Sheron N, Vettukattill JJ, et al. Hepatic changes in the failing Fontan circulation. Heart. 2007; 93:579-584. [PubMed: 17005713] 
19. Rychik J, Veldtman G, Rand E, et al. The precarious state of the liver after a Fontan operation: summary of a multidisciplinary symposium. Pediatric cardiology. 2012; 33:1001-12. [PubMed: 22534759]

20. Venkatesh SK, Yin M, Glockner JF, et al. MR elastography of liver tumors: preliminary results. AJR. American journal of roentgenology. 2008; 190:1534-40. [PubMed: 18492904]

21. Pereira AA, Mincis M, Novo NF, Altieri L. Serum activity of gamma-glutamyltranspeptidase, adult and fetal forms in patients with compensated and decompensated forms of alcoholic cirrhosis. AMB : revista da Associacao Medica Brasileira. 1986; 32:7-10. [PubMed: 2878473]

22. Nagatomo Y. Studies on the mechanism of gamma-glutamyltranspeptidase elevation in serum-concerning its hydrophobic and hydrophilic forms. Fukuoka igaku zasshi. 1987; 78:465-81. [PubMed: 2892766]

23. Font Alonso MJ, Ferrer A, Rodriguez Rosich A, Buti M, Rene JM. Usefulness of the GOT, GPT, and GGT parameters in determining the etiology of cirrhosis. Atencion primaria / Sociedad Espanola de Medicina de Familia y Comunitaria. 1989; 6:128-9. [PubMed: 2577522]

\section{Abbreviations list}

$\begin{array}{ll}\text { MRE } & \text { magnetic resonance elastography } \\ \text { MRI } & \text { magnetic resonance imaging } \\ \text { GRE } & \text { gradient recalled echo } \\ \text { kPa } & \text { kilopascals } \\ \text { AST } & \text { aspartate aminotransferase } \\ \text { ALT } & \text { alanine aminotransferase } \\ \text { INR } & \text { international normalized ratio } \\ \text { GGT } & \gamma \text {-glutamyl transferase } \\ \text { MELD } & \text { Model for End-Stage Liver Disease } \\ \text { VAST } & \text { varices, ascites, splenomegaly, thrombocytopenia } \\ \text { AP } & \text { atrio-pulmonary }\end{array}$




\section{Fontan Sub-types}

\section{Atrio-pulmonary \\ Lateral Tunnel \\ Extra-cardiac}
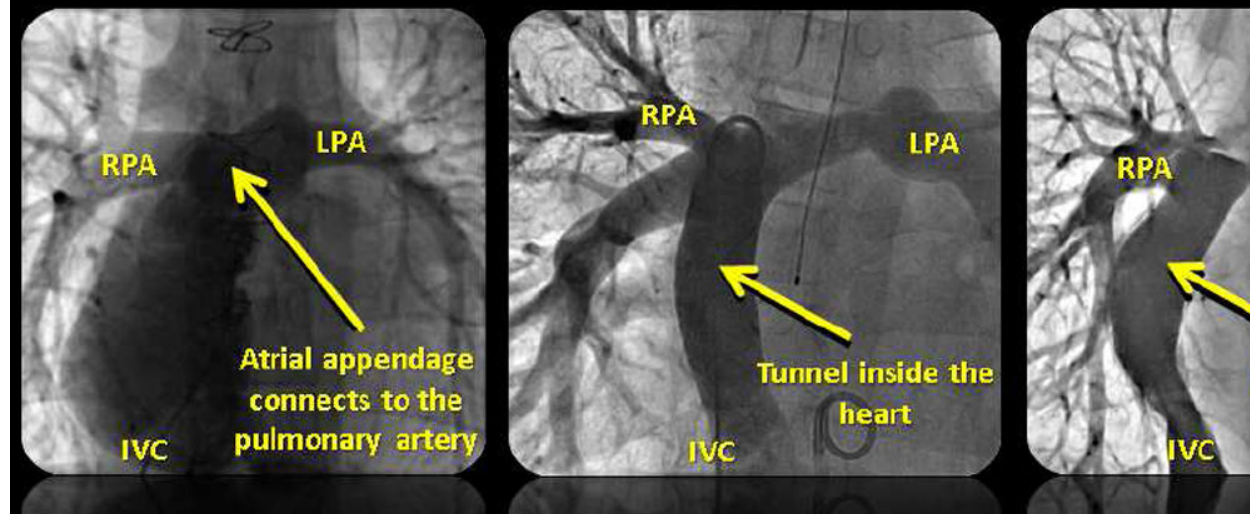

Surgical Era

\section{0 - 1990}

Figure 1. Fontan surgical subtypes

The Fontan operation consists of rerouting systemic bicaval venous return directly into the pulmonary arterial confluence, effectively bypassing the subpulmonary ventricle. These angiograms demonstrate the Fontan subtypes in order of the surgical era: atriopulmonary, in which the right atrial appendage is directly sewn to the pulmonary arterial confluence, the superior vena cava is left in continuity with the atrium, and the atrium acts as a functional conduit (left); lateral tunnel, in which the conduit lies within the right atrium, connecting the inferior vena cava (IVC) to the pulmonary artery (PA) and the superior vena cava is sewn directly to the right PA (middle); and the extracardiac type of Fontan connection, in which a conduit lying outside the heart connects the IVC to the inferior portion of the pulmonary arterial confluence and the superior vena cava is sewn directly to the right PA (right). 


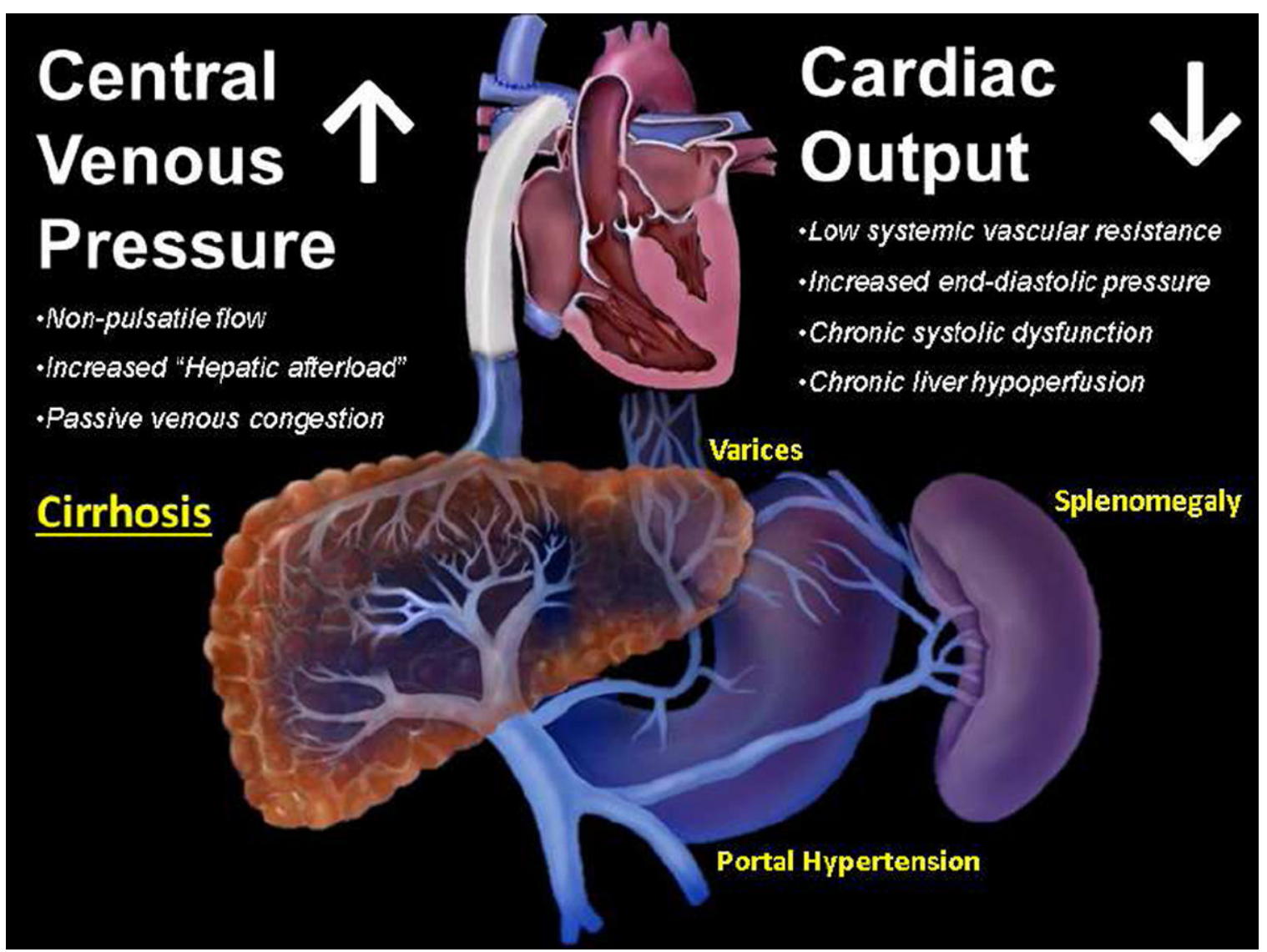

Figure 2. Fontan Operation and Pathophysiology of Cirrhosis In patients after Fontan operation, systemic venous return directly connects to the pulmonary arteries with non-pulsatile passive venous filling of the pulmonary arterial bed resulting in markedly elevated central venous pressure. Overtime, this elevated central venous pressure can increase the afterload experienced by the liver. In combination with the inherent low cardiac output state and chronic systolic and diastolic dysfunction of patients after Fontan operation, congestive hepatopathy can result. 


\section{Equipment or Control room}

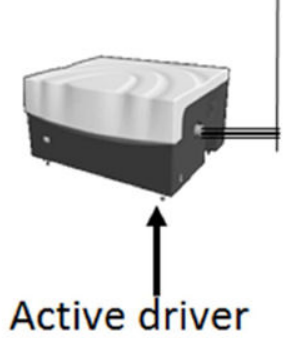

Figure 3. Magnetic Resonance Elastography - Patient Setup

A passive driver is placed on the upper right abdomen connected by plastic tubing to an active driver which transmits low frequency sounds waves via an audio subwoofer. ${ }^{10}$ 


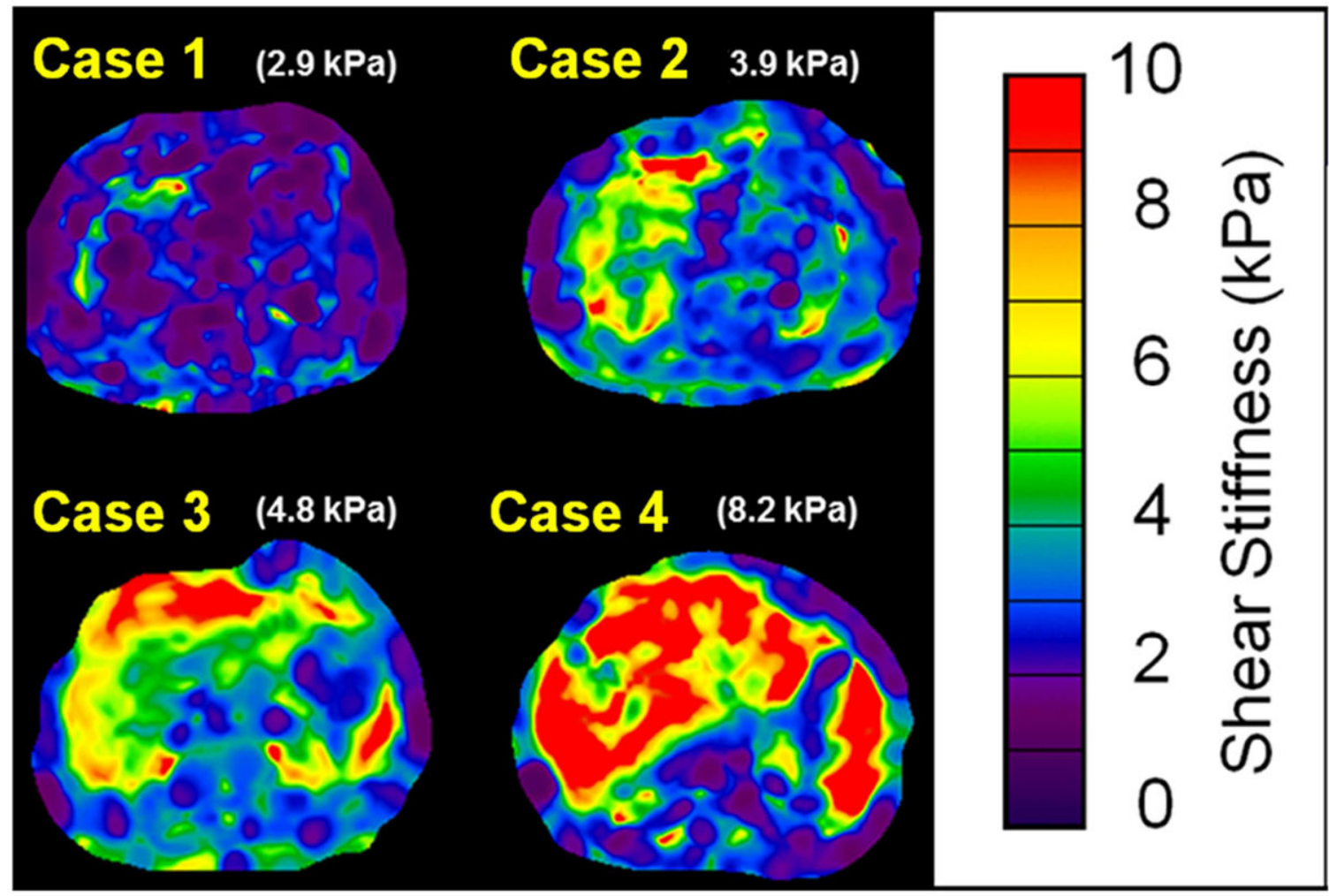

Figure 4. Interpretation of Elastograms

Shear stiffness maps from MREs of patients in this cohort demonstrating progressive mean liver stiffness. 

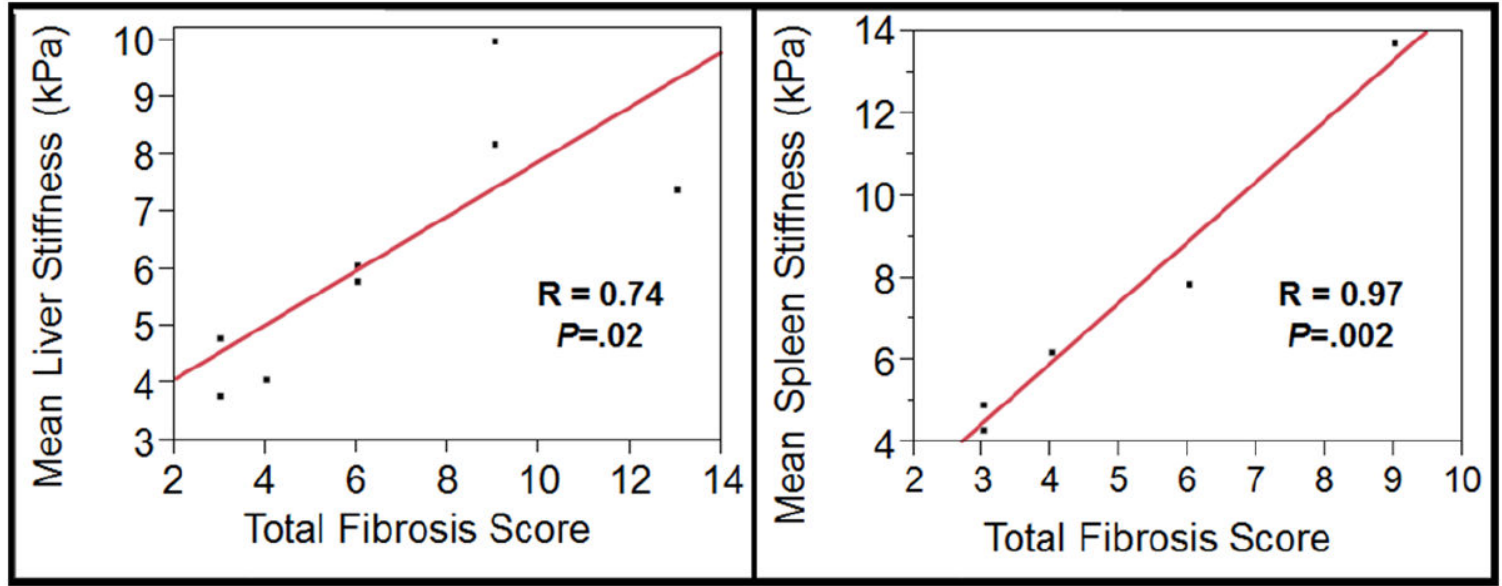

Figure 5. Liver Stiffness and Spleen Correlation with Liver Biopsy Total Fibrosis Score

Progressive MRE liver and spleen stiffness strongly correlated with liver biopsy derived total fibrosis score histologic grade of fibrosis $(\mathrm{R}=0.74, P=.02 ; \mathrm{R}=0.97, P=.002)$. Total fibrosis score was calculated by combining Ishtak portal fibrosis score, Scheuer portal fibrosis score, and sinusoidal fibrosis score. 


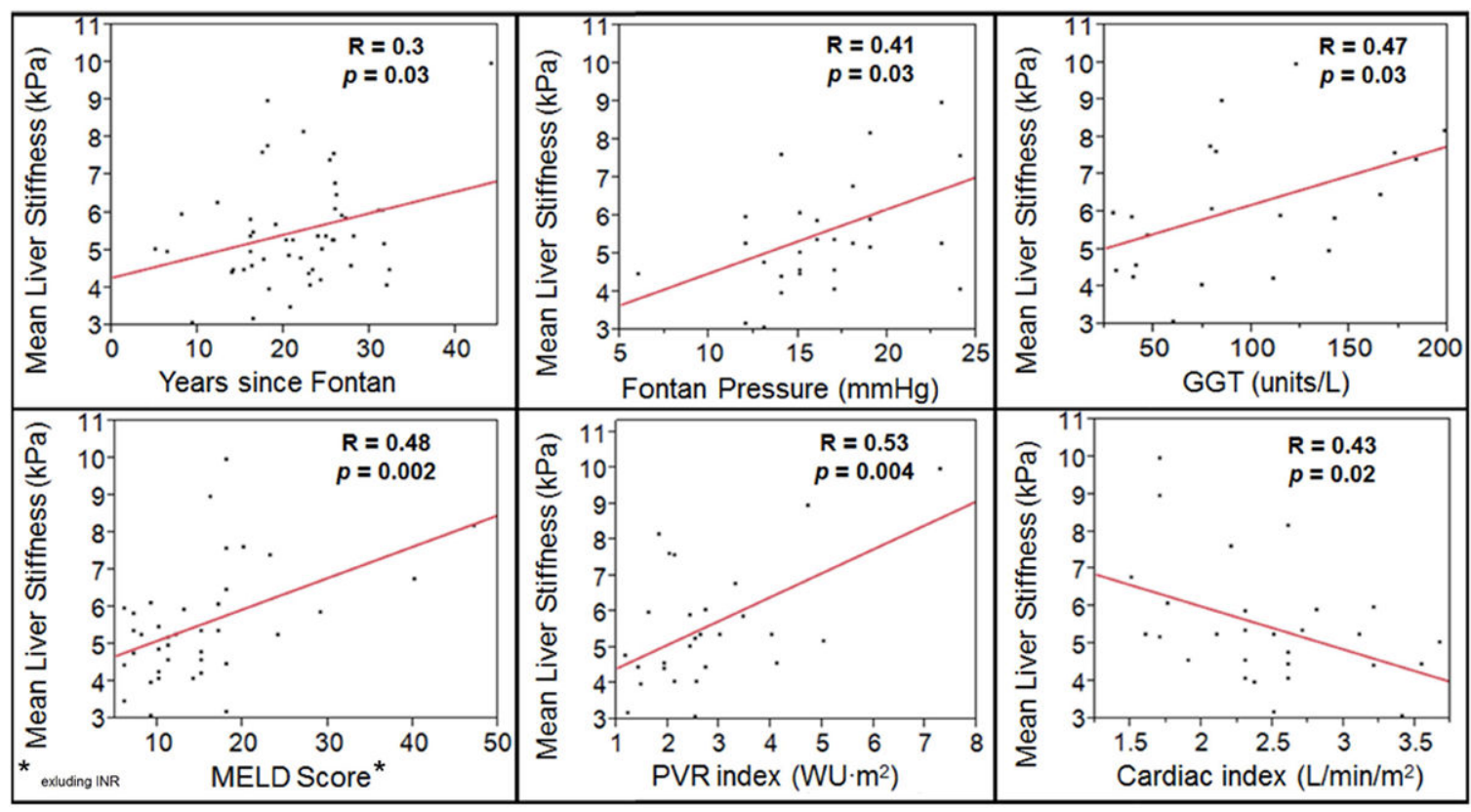

Figure 6. Clinical and Hemodynamic Correlation with Liver Stiffness

In univariate analysis linear regression analysis liver stiffness correlated with years since Fontan ( $\mathrm{R}=0.30 ; P=.03)$ (top left), Fontan pressure $(\mathrm{R}=0.41 ; P=.03)$ (top middle), GGT (R $=0.47 ; P=.03)$ (top right), MELD score $(\mathrm{R}=0.48 ; P=.002)$ (bottom left), and PVR index $(\mathrm{R}$ $=0.53 ; P=.004)$ (bottom middle) and inversely correlated with catheterization derived cardiac index $(\mathrm{R}=-0.43 ; P=.02)$ (bottom right). 


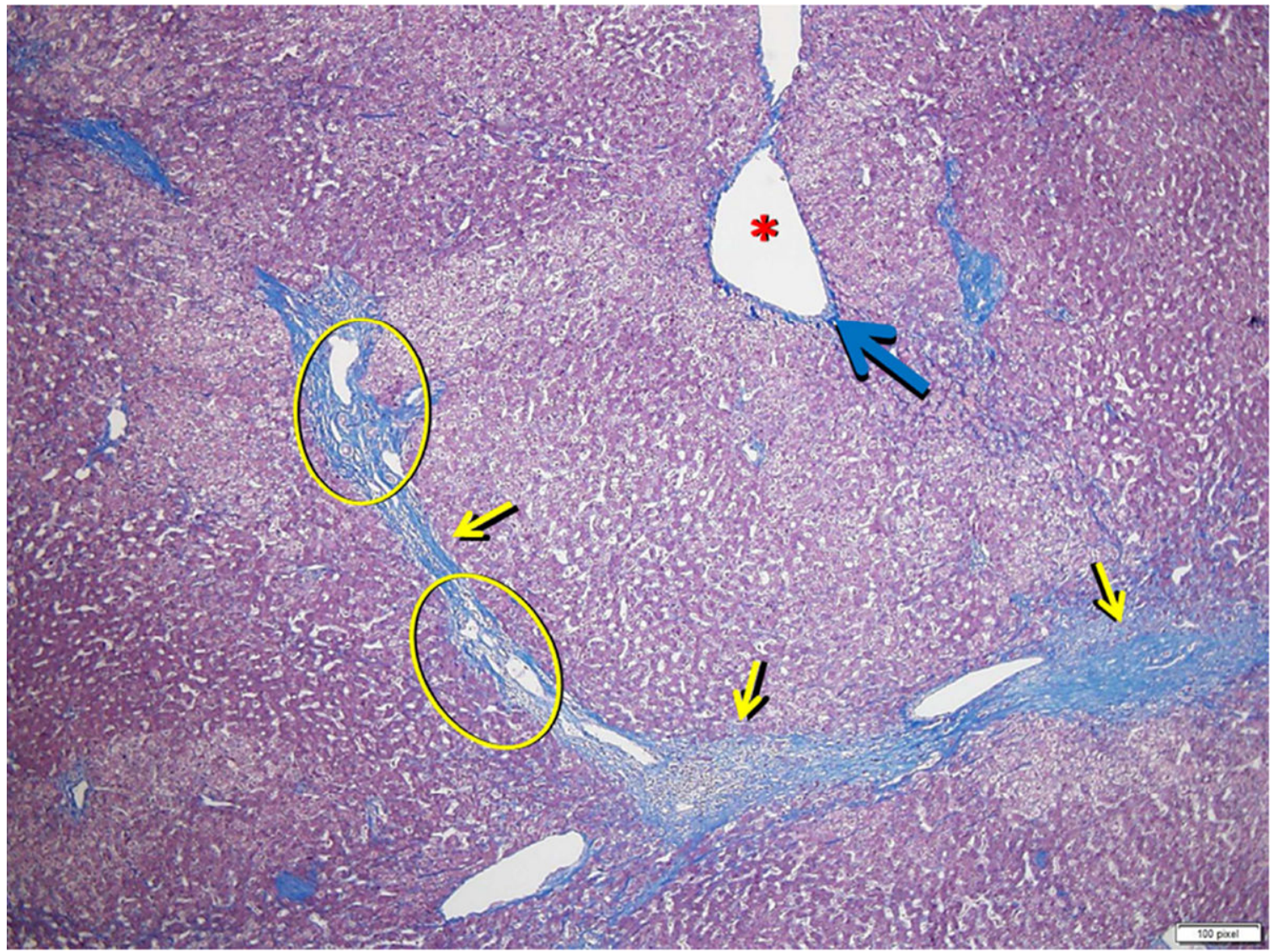

Figure 7. Typical Histologic Findings Fontan Related Cirrhosis

$40 \times$ magnification with Masson's trichrome stain showing bridging portal fibrosis (portal triads circled in yellow, bridging fibrosis: yellow arrows, central vein depicted by the red asterisk), and centrilobular perisinusoidal fibrosis (blue arrow). Sinusoidal hepatic cells are vulnerable to ischemic injury in low cardiac output as in the Fontan physiology. 


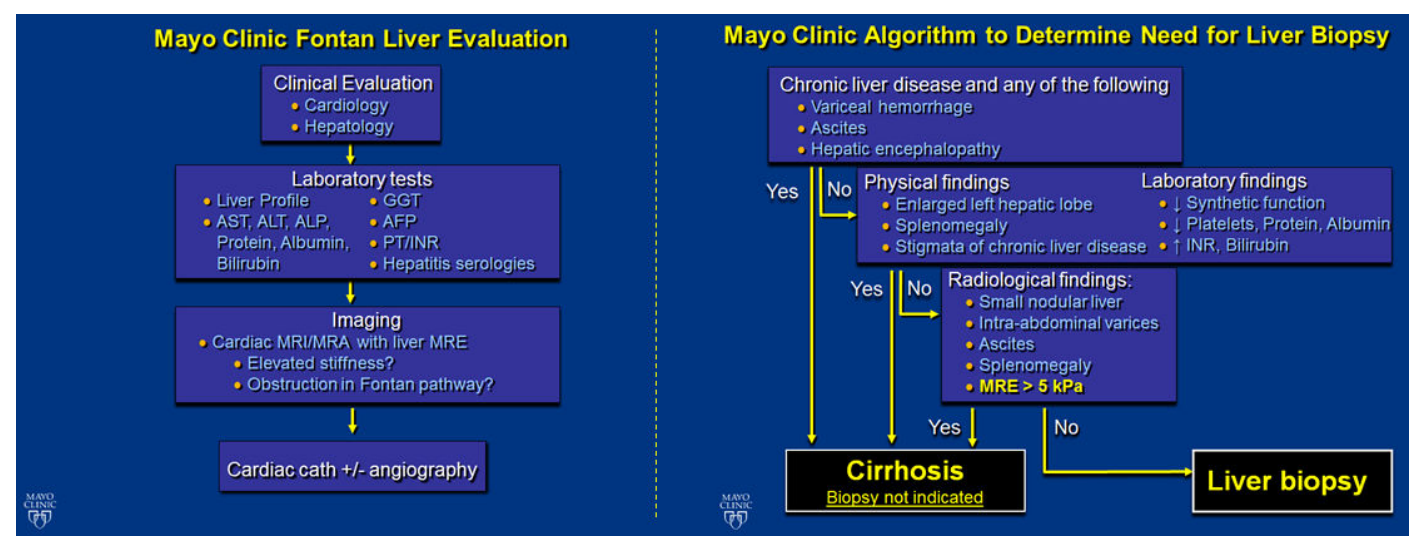

Figure 8. Proposed Mayo Clinic Fontan liver protocol This is the proposed Mayo Clinic algorithm for post-Fontan liver surveillance of cirrhosis (left) and Mayo Clinic Algorithm to Determine Need for Liver Biopsy (right). 


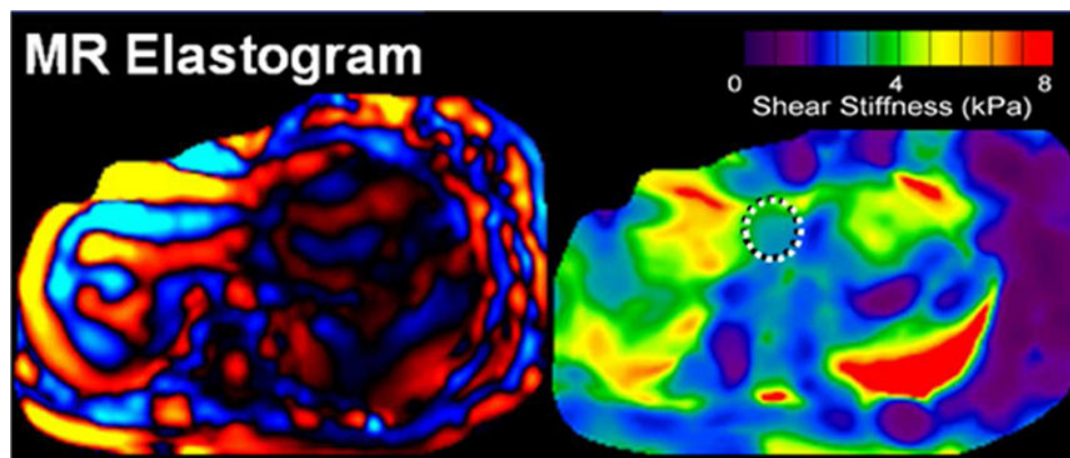

\section{Non- contrast}
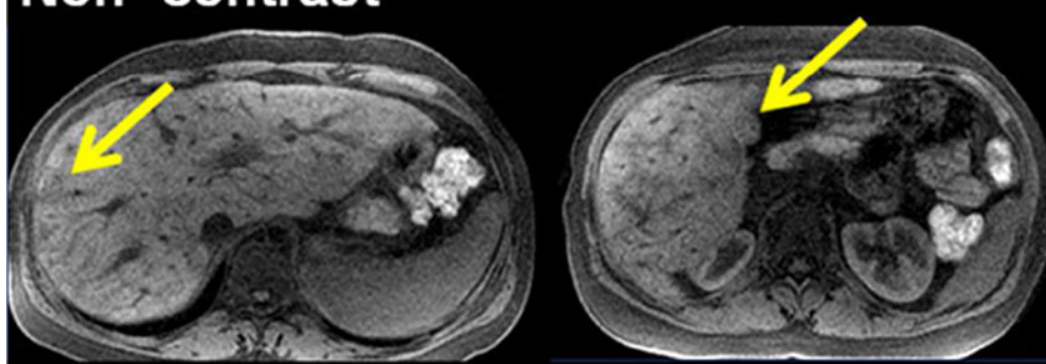

\section{Arterial phase}
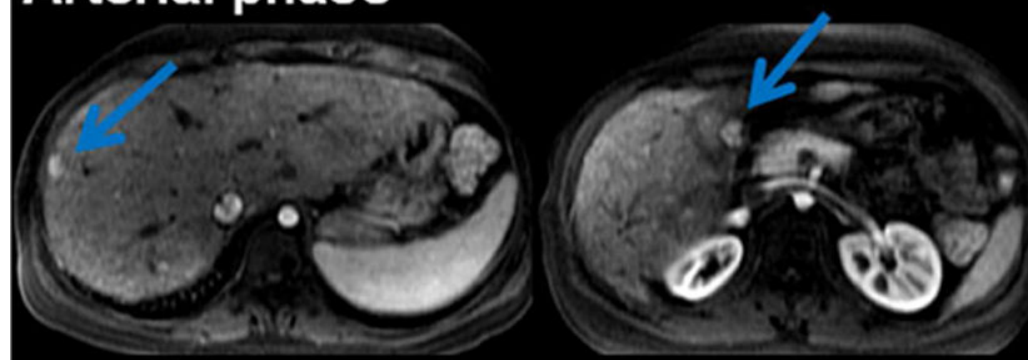

\section{Hepatocyte phase}

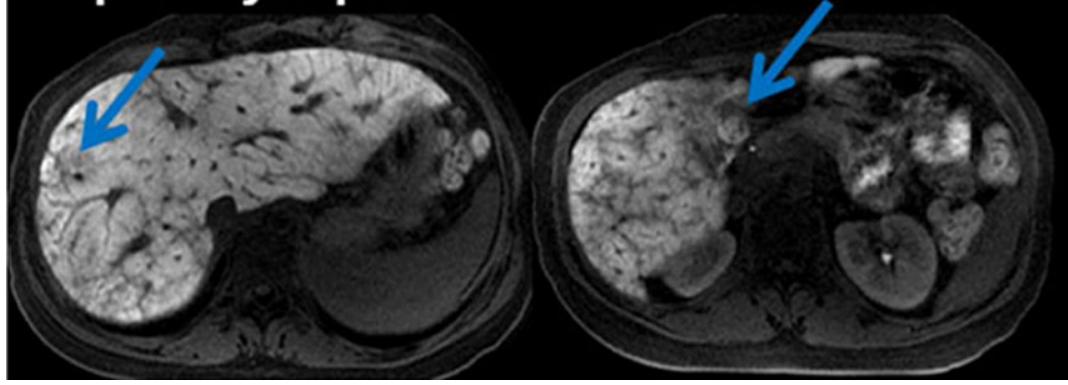

Figure 9. Case Example - 21 year Female with Liver Nodules on Ultrasound and Elevated Tumor Markers

Three hypervascular lesions in the liver [largest $=2.1 \times 1.6 \mathrm{~cm}$ (yellow arrows)]. Arterial phase: nodular enhancement. Venous-hepatocyte phase: uptake consistent with focal nodular hyperplasia (blue arrows). In hepatocellular carcinoma, uptake is absent. The elastogram (top row) shows normal stiffness $(2.8 \mathrm{kPa})$ in the area of the nodule (white dashed circle). In benign nodules, stiffness is normal, whereas in malignant nodules stiffness is severely 
elevated. Liver biopsy of this lesion confirmed focal nodular hyperplasia, consistent with the elastogram findings. ${ }^{9,19}$ 


\section{Table 1}

\section{Patient Characteristics ${ }^{a, b}$}

\begin{tabular}{ll}
\hline Variable & $(\mathbf{N}=\mathbf{5 0})$ \\
\hline Sex (female) & $25(50)$ \\
Age at Fontan (years) & $4(2-9)$ \\
Age at hepatology evaluation (years) & $25(21-33)$ \\
Interval post-Fontan to liver evaluation (years) & $22(16-26)$ \\
$\quad$ Atrio-pulmonary & $26(25-31)$ \\
$\quad$ Lateral Tunnel & $20(17-23)$ \\
$\quad$ Extracardiac & $16(9-17)$ \\
Single ventricle diagnosis: & \\
$\quad$ LV morphology & $30(60)$ \\
RV morphology & $20(40)$ \\
Fontan Type & \\
Atrio-pulmonary & $20(40)$ \\
$\quad$ Lateral tunnel & $17(34)$ \\
Extracardiac & $13(26)$ \\
Fenestrated & $17(34)$ \\
Heterotaxy & $6(12)$ \\
\hline$a$ LV = left ventricle; RV = right ventricle. & \\
$b$ Values are presented as mean \pm SD, No. (percentage), or as median (interquartile range).
\end{tabular}




\section{Table 2}

Hemodynamic and Imaging Data ${ }^{a, b}$

\begin{tabular}{|c|c|}
\hline Variable & \\
\hline Echocardiography data & $(\mathrm{N}=50)$ \\
\hline Ejection fraction & $52 \pm 11$ \\
\hline \multicolumn{2}{|l|}{ Systemic AV valve regurgitation grade } \\
\hline Trivial & $7(14)$ \\
\hline Mild & $34(68)$ \\
\hline Moderate & $7(14)$ \\
\hline Severe & $1(2)$ \\
\hline MRI data & $(\mathrm{N}=50)$ \\
\hline Cardiac index $\left(\mathrm{L} / \mathrm{min} / \mathrm{m}^{2}\right)$ & $2.8 \pm 1$ \\
\hline MR ejection fraction (\%) & $52 \pm 9$ \\
\hline Stroke volume $(\mathrm{ml})$ & $46 \pm 17$ \\
\hline ESV index $\left(\mathrm{ml} / \mathrm{m}^{2}\right)$ & $43 \pm 22$ \\
\hline EDV index $\left(\mathrm{ml} / \mathrm{m}^{2}\right)$ & $89 \pm 36$ \\
\hline Cardiac catheterization data & $(\mathrm{N}=30)$ \\
\hline Aortic oxygen saturation $(\%)$ & $90 \pm 5$ \\
\hline VEDP (mmHg) & $12 \pm 3$ \\
\hline Fontan pressure $(\mathrm{mmHg})$ & $16 \pm 4$ \\
\hline Pulmonary capillary wedge pressure $(\mathrm{mmHg})$ & $10 \pm 3$ \\
\hline Hepatic vein pressure $(\mathrm{mmHg})$ & $17 \pm 3$ \\
\hline Wedge hepatic venous pressure $(\mathrm{mmHg})$ & $19 \pm 5$ \\
\hline Hepatic venous pressure gradient $(\mathrm{mmHg})$ & $2 \pm 1$ \\
\hline Pulmonary arteriolar resistance index $\left(\mathrm{WU} \cdot \mathrm{m}^{2}\right)$ & $3 \pm 1$ \\
\hline Cardiac index (Fick) $\left(\mathrm{L} / \mathrm{min} / \mathrm{m}^{2}\right)$ & $2.4 \pm 0.6$ \\
\hline Fontan pathway stenosis & $11(22)$ \\
\hline Veno-venous collaterals & $24(48)$ \\
\hline
\end{tabular}

${ }^{a} \mathrm{AV}=$ atrioventricular; $\mathrm{MRI}=$ magnetic resonance imaging; $\mathrm{EF}=$ ejection fraction; $\mathrm{ESV}=$ end-systolic volume; EDV = end-diastolic volume; $\mathrm{VEDP}=$ ventricle end diastolic pressure $\mathrm{PA}=$ pulmonary artery $\mathrm{WU}=$ woods units; $\mathrm{AVM}=$ arteriovenous malformations.

${ }^{b}$ Values are presented as mean $\pm \mathrm{SD}$, or as No. (percentage). 
Table 3

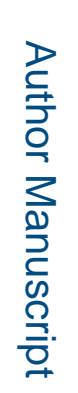

Liver Data ${ }^{a, b}$

\begin{tabular}{|c|c|c|}
\hline Variable & $(\mathrm{N}=\mathbf{5 0})$ & \\
\hline \multicolumn{3}{|c|}{ Secondary manifestations of cirrhosis } \\
\hline Splenomegaly & \multicolumn{2}{|l|}{$35(70)$} \\
\hline Varices & \multicolumn{2}{|l|}{$29(58)$} \\
\hline Ascites & \multicolumn{2}{|l|}{$23(46)$} \\
\hline Portal gastropathy & \multicolumn{2}{|l|}{$6(12)$} \\
\hline Hepatorenal syndrome & \multicolumn{2}{|l|}{$2(4)$} \\
\hline Hepatic encephalopathy & \multicolumn{2}{|l|}{$1(2)$} \\
\hline MRI findings & \multicolumn{2}{|l|}{$(\mathrm{N}=50)$} \\
\hline Nodularity & \multicolumn{2}{|l|}{$34(68)$} \\
\hline Caudate lobe hypertrophy & \multicolumn{2}{|l|}{$26(52)$} \\
\hline Lobar atrophy & \multicolumn{2}{|l|}{$19(38)$} \\
\hline Liver enlargement & \multicolumn{2}{|l|}{$30(60)$} \\
\hline Splenic volume $\mathrm{ml}^{3}$ & \multicolumn{2}{|l|}{$800(495-925)$} \\
\hline Portal vein diameter $>12 \mathrm{~mm}$ & \multicolumn{2}{|l|}{$16(32)$} \\
\hline No. of patients with nodules & \multicolumn{2}{|l|}{$13(26)$} \\
\hline Nodules & \multicolumn{2}{|l|}{$(\mathrm{N}=21)$} \\
\hline Hyper-enhancing nodules & \multicolumn{2}{|l|}{$13(62)$} \\
\hline Hepatocellular carcinoma & \multicolumn{2}{|l|}{$3(14)$} \\
\hline \multicolumn{2}{|l|}{ Laboratory tests } & Normal range \\
\hline GGT (U/L) & $96 \pm 54$ & $(7-50)$ \\
\hline $\mathrm{AST}(\mathrm{U} / \mathrm{L})$ & $43 \pm 31$ & $(8-43)$ \\
\hline $\operatorname{ALT}(\mathrm{U} / \mathrm{L})$ & $48 \pm 41$ & $(7-45)$ \\
\hline Alkaline phosphatase (U/L) & $141 \pm 121$ & $(37-98)$ \\
\hline Protein $(\mathrm{g} / \mathrm{dL})$ & $7 \pm 0.9$ & $(6.3-7.9)$ \\
\hline Albumin (g/dL) & $4.3 \pm 0.7$ & $(3.5-5.0)$ \\
\hline Total bilirubin (mg/dL) & $1.3 \pm 1$ & $(0.1-1.0)$ \\
\hline Direct bilirubin (mg/dL) & $0.4 \pm 0.3$ & $(0-0.3)$ \\
\hline Alpha-fetoprotein ${ }^{c}(\mathrm{ng} / \mathrm{mL})$ & $3.3 \pm 1.9$ & $(<0.6)$ \\
\hline Creatinine (mg/dL) & $1.0 \pm 0.5$ & $(0.6-1.1)$ \\
\hline Hemoglobin (g/dL) & $15 \pm 2.5$ & $(12-15.5)$ \\
\hline Platelets $(\times 109 / \mathrm{dL})$ & $155 \pm 52$ & $(150-450)$ \\
\hline $\mathrm{INR}^{d}$ & $2.4 \pm 0.6$ & $(0.8-1.2)$ \\
\hline $\mathrm{INR}^{e}$ & $1.4 \pm 0.5$ & $(0.8-1.2)$ \\
\hline \multicolumn{3}{|l|}{ Clinical scores } \\
\hline AST-Platelet ratio index & $0.4 \pm 0.2$ & $(<0.3)$ \\
\hline MELD Score & $15 \pm 9$ & $(<6)$ \\
\hline MELD-XI Score & $9 \pm 6$ & $(<11)$ \\
\hline
\end{tabular}




\begin{tabular}{lll}
\hline Variable & $(\mathbf{N}=\mathbf{5 0})$ & \\
CTP Score & $7 \pm 2$ & $(<5)$ \\
VAST Score & $2.1 \pm 1.1$ & $(<1)$ \\
\hline
\end{tabular}

${ }^{a} \mathrm{MRI}=$ magnetic resonance imaging; GGT $=\gamma$-glutamyl transferase; AST $=$ aspartate aminotransferase $;$ ALT $=$ alanine aminotransferase; INR = international normalized ratio; MELD = Model for End-Stage Liver Disease; MELD-XI = Model for End-Stage Liver Disease excluding INR; CTP $=$ Child-Turcotte-Pugh Classification; VAST = Varices, Ascites, Splenomegaly, and Thrombocytopenia .

${ }^{b}$ Values are presented as mean $\pm \mathrm{SD}$, as No. (percentage), or as median (interquartile range).

${ }^{c}$ Excluding patients with hepatocellular carcinoma.

$d_{\text {Patients receiving warfarin. }}$

$e_{\text {Patients not receiving warfarin. }}$ 


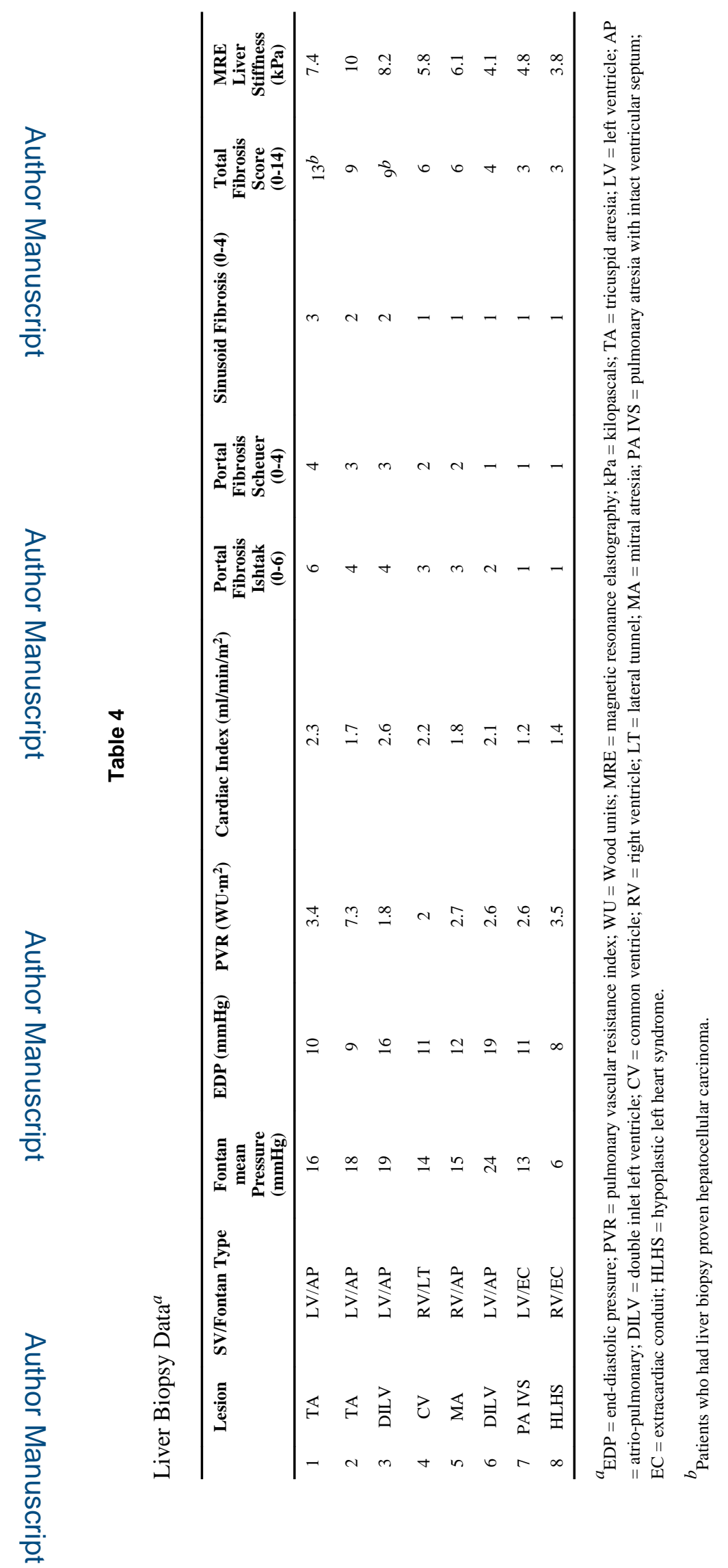

Mayo Clin Proc. Author manuscript; available in PMC 2016 July 01. 


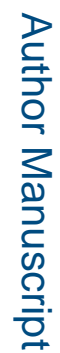

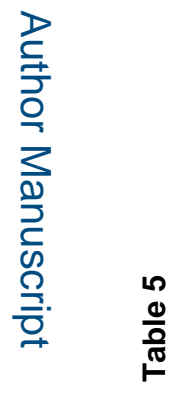

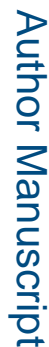

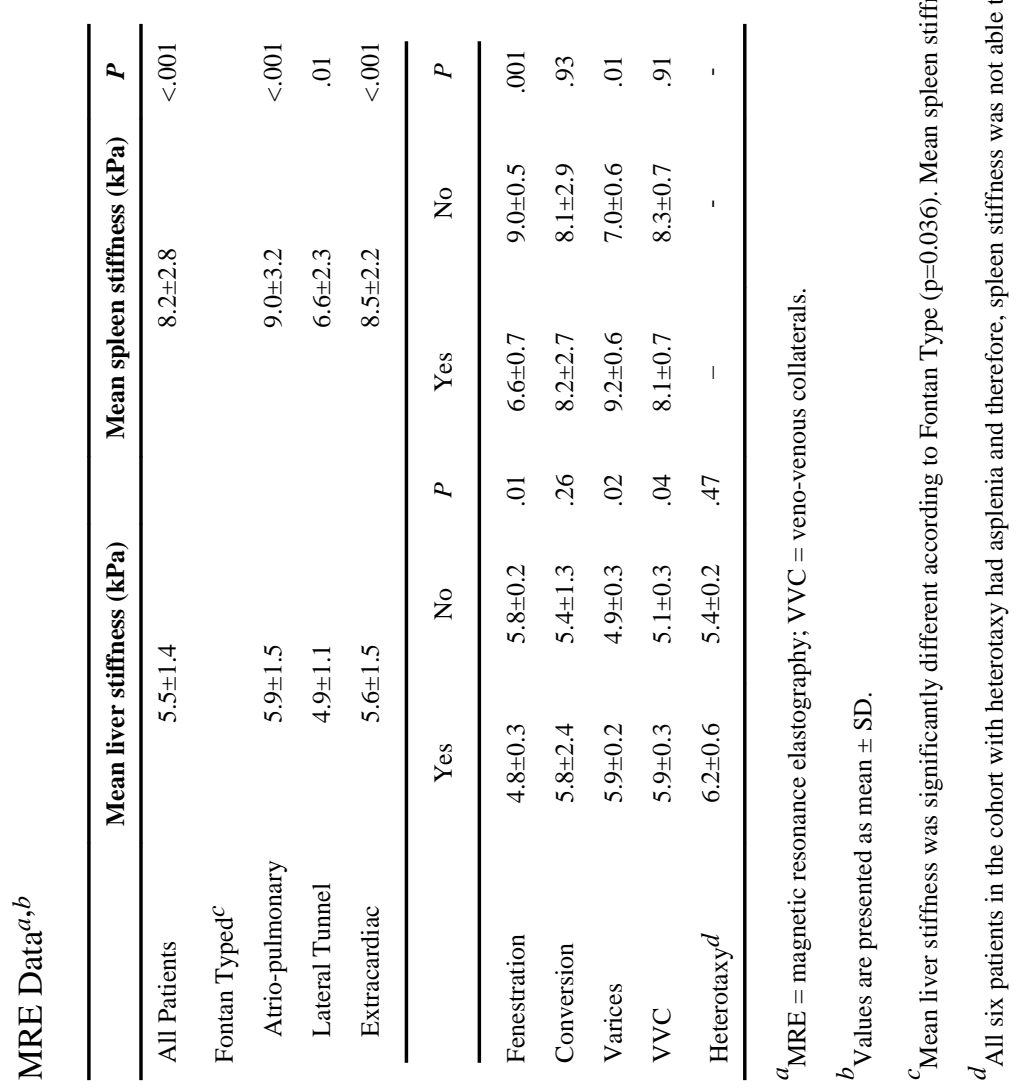

Mayo Clin Proc. Author manuscript; available in PMC 2016 July 01. 